\title{
OPEN Estimation and correction of instrument artefacts in dynamic impedance spectra
}

\author{
Collins Erinmwingbovo \& Fabio La Mantia ${ }^{凶}$
}

Dynamic impedance spectroscopy is one of the most powerful techniques in the qualitative and quantitative mechanistic studies of electrochemical systems, as it allows for time-resolved investigation and dissection of various physicochemical processes occurring at different time scales. However, due to high-frequency artefacts connected to the non-ideal behaviour of the instrumental setup, dynamic impedance spectra can lead to wrong interpretation and/or extraction of wrong kinetic parameters. These artefacts arise from the non-ideal behaviour of the voltage and current amplifier (I/E converters) and stray capacitance. In this paper, a method for the estimation and correction of high-frequency artefacts arising from non-ideal behaviour of instrumental setup will be discussed. Using resistors, $\left[\mathrm{Fe}(\mathrm{CN})_{6}\right]^{3-/ 4-}$ redox couple and nickel hexacyanoferrate nanoparticles, the effect of high-frequency artefacts will be investigated and the extraction of the impedance of the system from the measured dynamic impedance is proposed. It is shown that the correction allows acquiring proper dynamic impedance spectra at frequencies higher than the bandwidth of the potentiostat, and simultaneously acquire high precision cyclic voltammetry.

Electrochemical impedance spectroscopy (EIS) is a highly sensitive technique used for the elucidation of reaction mechanisms and determination of kinetic parameters ${ }^{1-3}$. The acquisition of qualitative and quantitative mechanistic information relies on the fitting of high-quality impedance data, acquired over a broad range of frequencies and potentials using physicochemical models ${ }^{2}$. However, cell and instrument setups have been reported as major sources of artefacts in impedance spectra ${ }^{4-6}$. These artefacts can result in the wrong interpretation of the reaction mechanism or the extraction of wrong kinetic parameters. Several methods for identifying artefacts arising from cell setup and procedures for avoiding and/or correcting these artefacts have been reported in literature ${ }^{4,5,7-13}$.

Following the works of Fletcher ${ }^{7}$ and Sadkowski et al. ${ }^{8}$, Battistel et al. proposed solutions to circumvent the artefacts occurring in a three-electrode cell setup ${ }^{4}$. It comprises of using a three-electrode cell in a coaxial geometry and a capacitive bridge between the working electrode and reference electrode ${ }^{4}$. Tran et al. with the help of simulations explained the use of low impedance reference electrode fabricated by connecting a platinum wire to the reference electrode through a capacitor, which has been used in circumventing high-frequency artefacts ${ }^{14-16}$. Low impedance reference electrodes were used to circumvent high-frequency artefacts during the acquisition of dynamic impedance spectra of cathode materials for aqueous batteries such as nickel hexacyanoferrate thin films and $\mathrm{LiMn}_{2} \mathrm{O}_{4}$ films ${ }^{17,18}$.

A zero-gap cell combined with by-pass modified and sensing electrodes was proposed by Stojadinovic and co-workers to minimize distortions arising from artefacts in a four-electrode cell setup ${ }^{10,19}$. The use of a fourprobe setup to measure high impedance values (up to $10 \mathrm{G} \Omega$ ) to circumvent artefacts arising from four-electrode cell setup has been demonstrated by Fafilek et al. ${ }^{5}$. Finite element method (FEM) simulations have also been used as a means of identifying limiting conditions for reliable impedance measurement in three-electrode cell setup for lithium-ion batteries ${ }^{20,21}$. To avoid artefacts arising from geometric and electrochemical asymmetries, Klink et al. suggested the use of modified Swagelok cells with precisely aligned electrodes and a coaxially located reference electrode ${ }^{22}$.

The aforementioned methods reduce and/or eliminate artefacts arising from cell setups, but they do not address artefacts arising from the instrument setup. The instrument setup used for the data acquisition in EIS contains parts (cables, voltage and current amplifiers), which deviates from ideal behaviour at high frequencies ${ }^{4}$. Manufacturers use calibration to reduce such artefacts at high frequencies ${ }^{23}$. In classic EIS, data acquisition parameters, among which the current amplifier, are automatically optimized for each frequency by the software, thereby reducing instrumental artefacts. This is not possible in dynamic impedance spectroscopy, in which the 


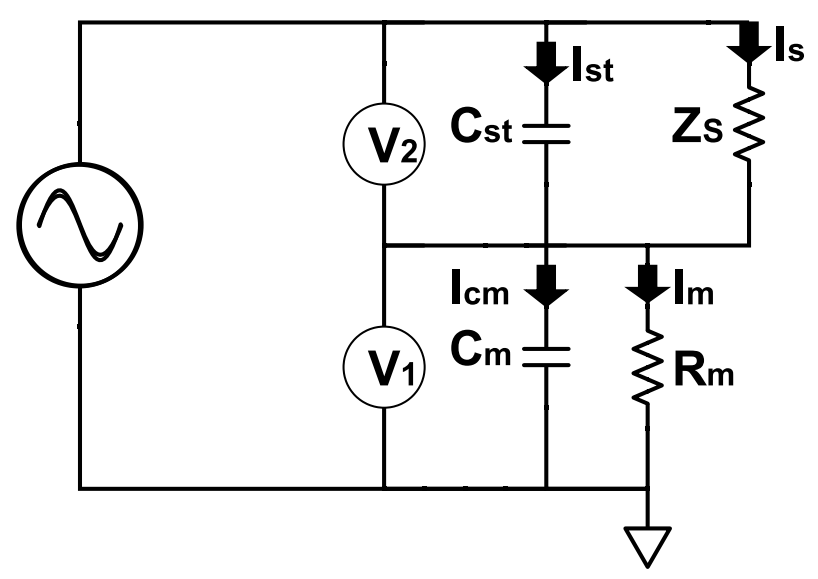

Figure 1. Simplified schematic diagram of a potentiostat in a two-electrode cell setup used for measuring the transimpedance and stray capacitance of the potentiostat used in this work. $Z_{s}$ denotes the impedance of the system being measured, $I_{s}$ is the current flowing through $Z_{s}, C_{s t}$ is the stray capacitance and $I_{s t}$ is the current flowing through $C_{s t} . R_{m}$ is the current measuring resistor, $V_{2}$ denotes the voltage drop across $Z_{s}$ and $C_{s t}$, while $V_{1}$ denotes the voltage drop across $R_{m}$ and $C_{m} . I_{c m}$ and $I_{m}$ represent the current flowing through $C_{m}$ and the measured current respectively.

perturbation signal contains all the frequencies at once. Dynamic impedance spectroscopy has been reported as a better alternative for investigating the kinetics of unstable electrochemical systems and electrochemical systems under non-stationary conditions $\mathrm{s}^{17,18,24-37}$. However, instrumental artefacts are particularly troublesome in dynamic impedance spectroscopy due to two contrasting requirements: on one side the acquisition of good $\mathrm{dc}$ data (cyclic voltammetry) requires the selection of a low-current amplifier; on the other side, to reach high frequencies a high-current amplifier with high bandwidth has to be chosen.

In this paper, we show how, by estimating the transimpedance response of the instrument, it is possible to correct the instrumental artefacts at high frequencies and increase the bandwidth of the current amplifier. In particular, we will illustrate as practical examples, the measurement of dynamic impedance spectra of redox couples in solution and potassium (de-)insertion in nickel hexacyanoferrate.

Sources of instrumental artefacts. Instrument setups used for acquisition of impedance spectra such as potentiostats contain components (voltage and current amplifiers), which deviate from their ideal behaviour at high frequencies thereby introducing artefacts to the measured impedance. The current amplifier of the potentiostat measures the current as a voltage drop through a resistor $R_{m}$. Switchable resistors of different magnitude are used to cover different current ranges, thus allowing for high precision measurements ${ }^{38}$. The value of $R_{m}$ determines also the voltage per full current range of the current amplifier, which in the instrument used in this work is $1 \mathrm{~V}$. As an example, this translates to $R_{m}$ equal to $1 \mathrm{k} \Omega$ when the current range of $1 \mathrm{~mA}$ is selected. The achievable gain of the current amplifier depends on the input impedance (measured impedance) and the transimpedance of the $I / E$ converter. The bandwidth of the $I / E$ converter depends on the gain such that the greater the gain (lower current range), the lower the bandwidth of the $I / E$ converter. Measuring impedance at frequencies approaching or exceeding the bandwidth of the $I / E$ converter could result in the introduction of artefacts arising from the instrumentation. Therefore, it is important to investigate the bandwidth of the $I / E$ converter at different current ranges to properly choose it in connection to the perturbation signal.

The voltage signal applied to the cell at high-frequency by the control loop in the potentiostat may be shifted in phase due to its response bandwidth ${ }^{39}$. The use of larger inputs and monitoring of the feedback signal to the cell has been suggested for circumventing this problem ${ }^{2,39}$. Another source of artefacts in impedance measurements connected to both instrument and cell setups is the stray capacitance. Stray capacitances have been reported to occur between CE-RE, RE-ground, RE-WE and WE-ground ${ }^{23}$. Despite the calibration done by manufacturers to eliminate these stray capacitance, it has been reported that electrochemical cells affect the value of the stray capacitances ${ }^{23}$. Here, as a low-impedance RE is used in the experiments, it is possible to ignore the stray capacitances between CE-RE and RE-ground, as explained in literature ${ }^{23}$.

Theoretical description of the potentiostat. Figure 1 shows the electric circuit of a potentiostat in a two-electrode cell configuration. $Z_{s}$ in Fig. 1 is the impedance of the system being measured while $C_{s t}$ is the stray capacitance between the WE-CE/RE. This is the stray capacitance of interest as the effect of the other stray capacitance in the potentiostat (stray capacitance from RE-ground and from RE-CE) becomes negligible when a low impedance RE is used ${ }^{23}$. The measured impedance $\left(Z_{m}\right)$ can be described as $^{23}$ :

$$
Z_{m}=\frac{V_{2}}{I_{m}}=\frac{V_{2}}{V_{1}} R_{m}
$$


where $V_{2}$ is the voltage drop across $Z_{s}$ and $C_{s t}$ while $I_{m}$ is the measured current. $V_{2}$ can be described as:

$$
V_{2}=I_{s} Z_{s} Z_{V_{2}}=\frac{I_{s t}}{j \omega C_{s t}} Z_{V_{2}}
$$

where $I_{s}$ and $I_{s t}$ are the current flowing through $Z_{s}$ and $C_{s t}$ respectively. $Z_{V_{2}}$ is the transimpedance of the electrometer $\left(V_{2}\right)$ which is unknown. $V_{1}$, which measures the current as a voltage drop across $R_{m}$ is given by:

$$
V_{1}=I_{m} Z_{V_{1}} R_{m}=I_{C m} \frac{1}{j \omega C_{m}} Z_{V_{1}}
$$

where $Z_{V_{1}}$ is the impedance of $V_{1}$ and $I_{C m}$ is the current flowing through $C_{m}$. Equation (1) can then be rewritten as:

$$
Z_{m}=\frac{I_{s} Z_{s} Z_{V_{2}}}{I_{m} Z_{V_{1}}}
$$

The total current $\left(I_{T}\right)$ is given by $I_{T}=I_{s}+I_{s t}=I_{m}+I_{C m}$, subsequently $I_{T}=I_{m}\left(1+j \omega C_{m} R_{m}\right)$ and $I_{m}=I_{T} /\left(1+j \omega C_{m} R_{m}\right)$. Defining $Z_{V_{1}}^{\prime}=Z_{V_{1}} /\left(1+j \omega C_{m} R_{m}\right)$, Eq. (4) can be rewritten as:

$$
\begin{gathered}
Z_{m}=\frac{I_{s} Z_{s} Z_{V_{2}}}{I_{T} Z_{V_{1}}^{\prime}} \\
Z_{m}=\frac{I_{s} Z_{s} Z_{V_{2}}}{\left(I_{s t}+I_{s}\right) Z_{V_{1}}^{\prime}} \\
\frac{1}{Z_{m}}=\frac{Z_{V_{1}}^{\prime}}{Z_{V_{2}} Z_{s}}+\frac{I_{s t} Z_{V_{1}}^{\prime}}{I_{s} Z_{s} Z_{V_{2}}} \\
\frac{Z_{s}}{Z_{m}}=\frac{Z_{V_{1}}^{\prime}}{Z_{V_{2}}}+\frac{I_{s t} Z_{V_{1}}^{\prime}}{I_{s} Z_{V_{2}}}
\end{gathered}
$$

Redefining $I_{s}$ and $I_{s t}$ from Eq. (2) will lead to $I_{s}=V_{2} / Z_{V_{2}} Z_{s}$ and $I_{s t}=V_{2} j \omega C_{s t} / Z_{V_{2}}$. Substituting the term $I_{s t} / I_{s}$ in Eq. (8) with $j \omega C_{s t} Z_{s}$ leads to:

$$
\frac{Z_{s}}{Z_{m}}=\frac{Z_{V_{1}}^{\prime}}{Z_{V_{2}}}+\frac{j \omega C_{s t} Z_{s} Z_{V_{1}}^{\prime}}{Z_{V_{2}}}
$$

The transimpedance of the potentiostat $Z_{t r}$ can be defined as $Z_{t r}=Z_{V_{1}}^{\prime} / Z_{V_{2}}$. Subsequently, Eq. (9) results to:

$$
\frac{Z_{s}}{Z_{m}}=Z_{t r}\left(1+j \omega C_{s t} Z_{s}\right)
$$

Equation (10) indicates a linear relationship between the relative admittance of the system being measured $\left(Z_{s} / Z_{m}\right)$ and $Z_{s} . Z_{t r}$ is frequency-dependent and extrapolated at each frequency as explained in S2 of the supporting information, while $C_{s t}$ reported in this paper is an average of the $C_{s t}$ at different current ranges.

\section{Results and discussions}

Extracting the transimpedance and stray capacitance. To extract the transimpedance of the potentiostat $\left(Z_{t r}\right)$ and stray capacitance $\left(C_{s t}\right)$, the impedance of high precision resistors at different current ranges of the potentiostat from ten times to one-tenth of the corresponding $R_{m}$ of the current range was measured. $Z_{t r}$ and $C_{s t}$ were extracted from the intercept and slope of the first-order polynomial fit of the relative admittance $\left(Z_{s} / Z_{m}\right)$ versus $Z_{s}$ according to Eq. (10). The stray capacitance due to the potentiostat and cell setup $C_{s t}$ is obtained from the slope of the plot of the high-frequency data point of $j \omega C_{s t}$ versus $\omega$ (Fig. S2 in the supporting information). The stray capacitance $\left(C_{s t}\right)$ was estimated to be $240 \pm 5 \mathrm{pF}$.

Bandwidth of the potentiostat. The bandwidth of the potentiostat in terms of the transimpedance $\left(Z_{t r}\right)$ at different current ranges is shown in Fig. 2. Ideally, $\left|Z_{t r}\right|$ should be unitary at all frequencies. However, the result shows that the bandwidth (frequency where the modulus of $Z_{t r}$ deviates from the ideal unitary value of $-30 \%$ ), decreases from $800 \mathrm{kHz}$ to $8 \mathrm{kHz}$ when current range decreases from $1 \mathrm{~mA}$ to $1 \mu \mathrm{A}$ as expected.

Extracting impedance of the system from measured impedance. The impedance of the various electrochemical systems (resistors at different current ranges, $\left[\mathrm{Fe}(\mathrm{CN})_{6}\right]^{3-/ 4-}$ redox couple and nickel hexacyanoferrate) devoid of the instrumental artefacts were extracted from the measured impedance using Eq. (11) and the estimated $C_{s t}$ of the potentiostat and $Z_{t r}$ of the current range of interest. 


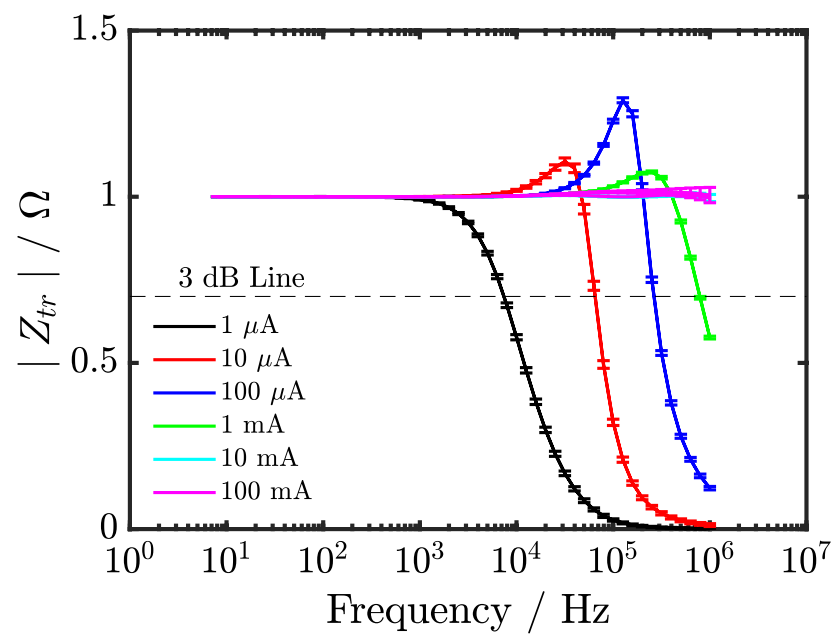

Figure 2. The plot of the magnitude of the transimpedance of the potentiostat $\left(\left|Z_{t r}\right|\right)$ at different current range versus frequency. The plot shows the $3 \mathrm{~dB}$ line, which allows for the bandwidth of the potentiostat at different current ranges to be read off.
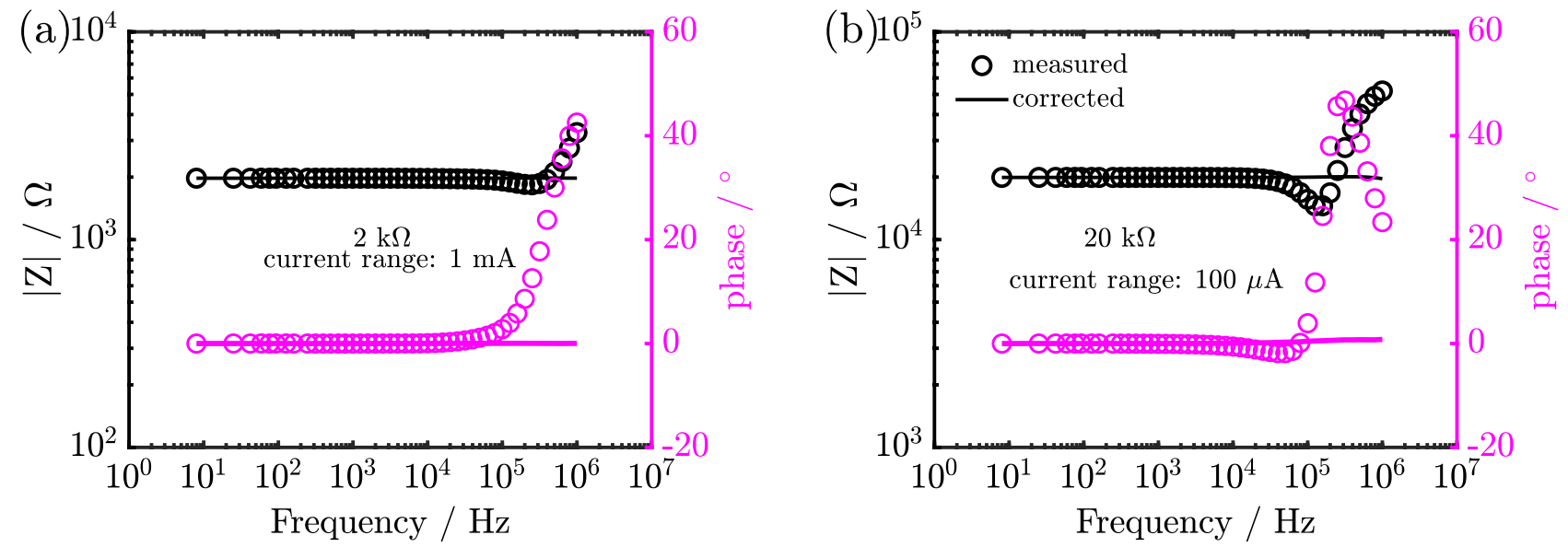

Figure 3. Correction method applied to $2 \mathrm{k} \Omega$ at $1 \mathrm{~mA}$ and $20 \mathrm{k} \Omega$ at $100 \mu \mathrm{A}$ current range. circle represents the measured impedance, while dash line represents the corrected impedance using the proposed method.

$$
Z_{\text {corr }}=\frac{Z_{t r} Z_{m}}{1-j \omega C_{s t} Z_{m} Z_{t r}}
$$

Resistor. The use of Eq. (11) to obtain the real impedance from the measured impedance of various resistors is illustrated in this section of the paper. The magnitude and phase of the impedance of $2 \mathrm{k} \Omega$ at $1 \mathrm{~mA}$ and $20 \mathrm{k} \Omega$ at $100 \mu \mathrm{A}$ current range is shown in Fig. 3.

Ideally, the magnitude of the impedance of a resistor is constant and the phase is zero at all frequencies. The measured impedance (circle in Fig. 3) was observed to deviate from its constant magnitude and zero phase at ca. $100 \mathrm{kHz}$ in both cases. The deviation can be attributed to instrument artefacts. Using the correction method, the real impedance (unitary magnitude and zero phase at all frequencies) can be extracted (continuous lines in Fig. 3). This illustrates that the proposed correction method can be used for extending digitally the bandwidth of the potentiostat. The limit of the correction method for the different current ranges is shown in section S3 of the supporting information.

Redox couple. The effect of instrument artefacts and application of the proposed correction method was also investigated using a $\left[\mathrm{Fe}(\mathrm{CN})_{6}\right]^{3-/ 4-}$ redox couple on a $250 \mu \mathrm{m}$ Pt electrode in a three-electrode cell configuration. The dynamic impedance spectra were recorded during quasi-cyclic voltammetry, as explained in ${ }^{31,32,35}$. In this case, as discussed previously, the current range has to be selected to obtain undistorted spectra at highfrequency and simultaneously have good quality dc data (quasi-cyclic voltammetry). The uncompensated cell resistance was $275 \Omega$, in agreement with the conductivity of the solution and the dimension of the working electrode. For measuring such resistance properly at $1 \mathrm{MHz}$, a current range of $10 \mathrm{~mA}$ ought to be used. However, as seen in Fig. 4a, the use of $10 \mathrm{~mA}$ current range would strongly reduce the quality of the extracted voltammo- 

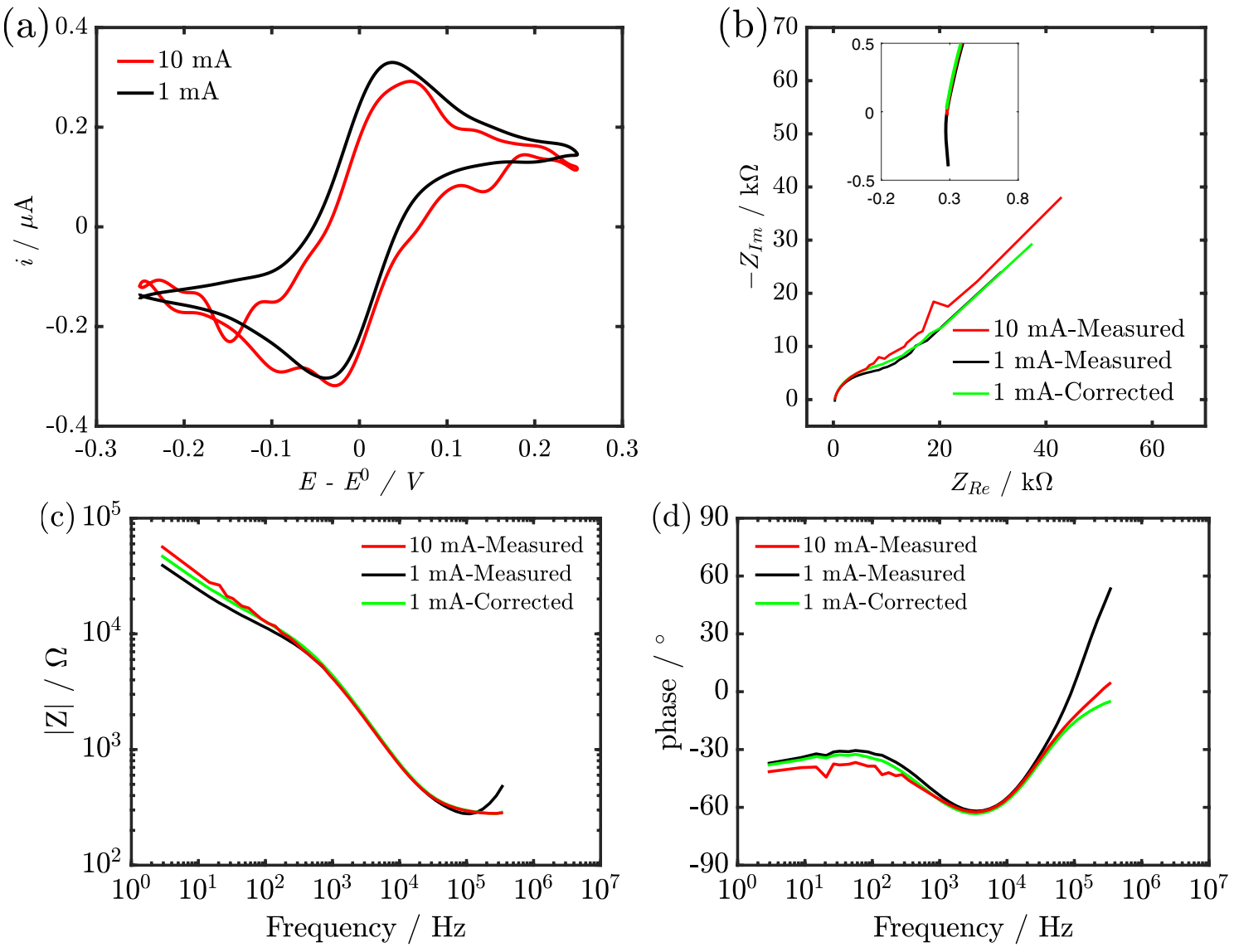

Figure 4. (a) Quasi Voltammogram obtained at the different current range for $250 \mu \mathrm{m}$ Pt electrode in $5 \mathrm{mM}$ $\mathrm{K}_{3}\left[\mathrm{Fe}(\mathrm{CN})_{6}\right]$ solution with $1 \mathrm{M} \mathrm{KCl}$ as supporting electrolyte. (b) Nyquist plot of impedance spectra obtained for $250 \mu \mathrm{m}$ Pt electrode in $5 \mathrm{mM} \mathrm{K}_{3}\left[\mathrm{Fe}(\mathrm{CN})_{6}\right]$ solution with $1 \mathrm{M} \mathrm{KCl}$ as supporting electrolyte using $1 \mathrm{~mA}$ and $10 \mathrm{~mA}$ current range with an insert showing the high-frequency region. (c) and (d) Magnitude (| $Z \mid)$ and Phase of impedance spectra obtained for $250 \mu \mathrm{m}$ Pt electrode in $5 \mathrm{mM} \mathrm{K}_{3}\left[\mathrm{Fe}(\mathrm{CN})_{6}\right]$ solution with $1 \mathrm{M} \mathrm{KCl}$ as supporting electrolyte using $1 \mathrm{~mA}$ and $10 \mathrm{~mA}$ current range.

gram. It is important to highlight that the reduced data quality of the voltammogram at $10 \mathrm{~mA}$ does not originate from interactions between the ac and dc signal as shown in section S4 of the supporting information but from the precision of the current amplifier.

Repeating the same experiment with a $1 \mathrm{~mA}$ current range improves noticeably the data quality. However, it introduces a distortion connected to the transimpedance of the potentiostat in the form of an inductive component, as observable in the inset in Fig. $4 \mathrm{~b}$ and the magnitude and phase of the impedance shown in Fig. $4 \mathrm{c}, \mathrm{d}$ respectively. It is assumed that the potentiostat is at virtual ground and the current is then measured as the voltage drop across $R_{m}$. However, this is not the case as the frequency increases, rather the characteristic of the current amplifier at high frequencies resembles that of an inductor, hence the potentiostat, in reality, controls the current via an RLC element ${ }^{6}$. The inductive component in the measured impedance, which is an artefact from the current amplifier due to the usage of an inappropriate current range ( $1 \mathrm{~mA})$, can be compensated by $Z_{V_{1}}$, which is one of the components of $Z_{t r}$. Using the proposed correction method (Eq. (11)) and the extracted $Z_{t r}$ for $1 \mathrm{~mA}$ current range, the real impedance can be extracted from the measured impedance as shown in the inset of Fig. 4b (green curve), and Fig. 4c,d. The result indicates that the proposed correction method allows choosing an appropriate current range, without compromising the high-frequency data in the impedance spectra, thus enabling the measurement of dynamic impedance at high-frequency. This is particularly important in the analysis of adsorption phenomena and the study of the double layer at microelectrodes.

Nickel hexacyanoferrate nanoparticles. In this section, we illustrate furthermore the effect of instrumental artefacts on the data evaluation of more complex systems. The system of choice is nickel hexacyanoferrate $(\mathrm{NiHCF})$ nanoparticles, which have been reported as a promising cathode material for aqueous and nonaqueous battery systems $\mathrm{s}^{40,41}$ and lithium recovery ${ }^{41-48}$.

For intercalation materials such as NiHCF nanoparticles, the impedance is normally acquired over a wide range of frequencies as it allows for the study of the various physicochemical processes occurring during the intercalation process such as (de)adsorption, interfacial charge transfer and mass transport in the solid. The Nyquist plot of the impedance spectra in Fig. 5a shows two RC time constants followed by a straight line attributed to mass transport in the solid. A comparison of the high-frequency data points between the measured 

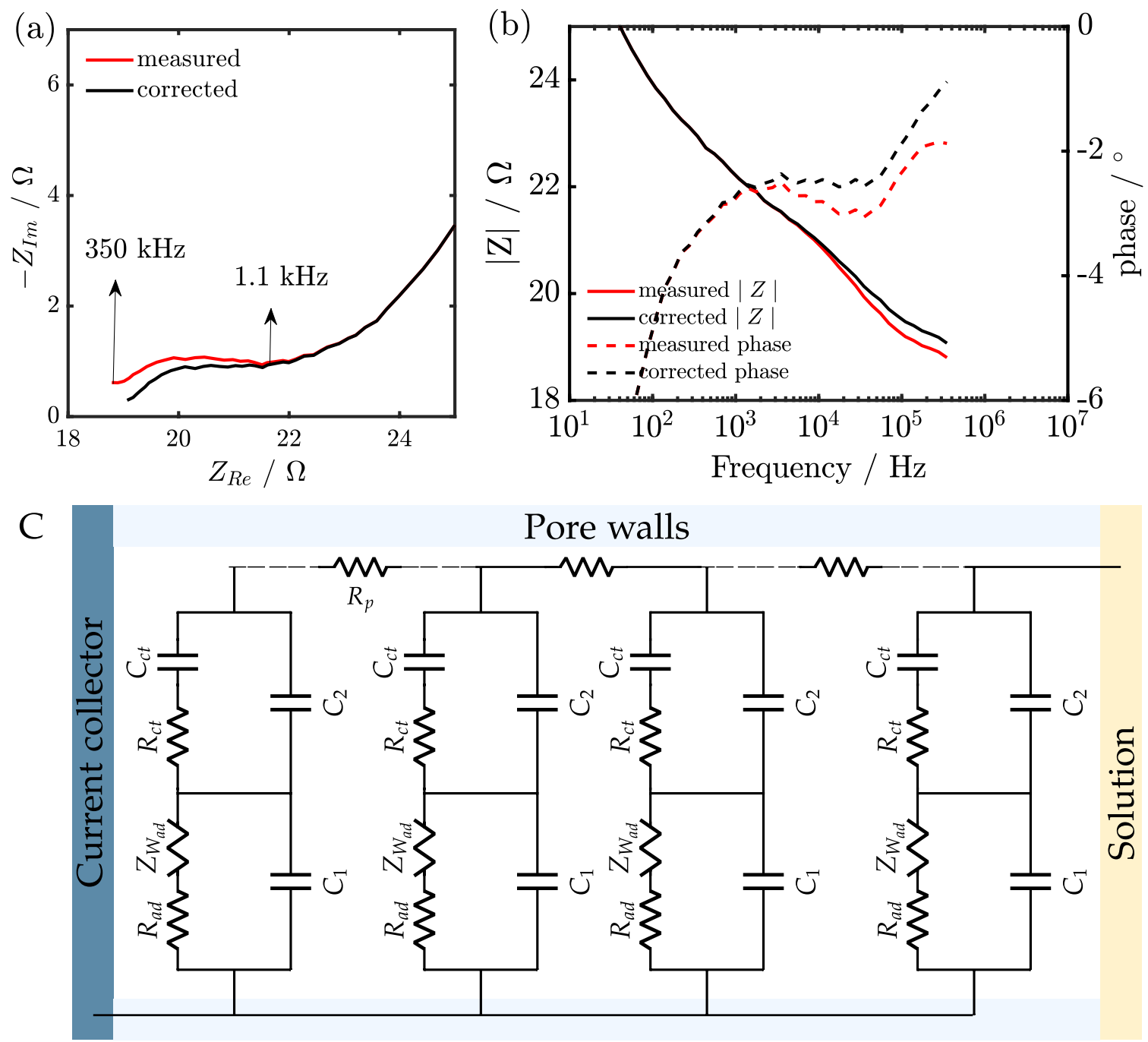

Figure 5. (a) and (b) Nyquist plot and Bode plot of NiHCF nanoparticles in $0.5 \mathrm{M} \mathrm{K}_{2} \mathrm{SO}_{4}$ within the frequency range of $350 \mathrm{kHz}$ to $2.8 \mathrm{~Hz}$ at $0.50 \mathrm{~V}$ during the cathodic scan respectively. (c) Equivalent circuit of the porous electrode including the equivalent circuit obtained from modelling the reversible insertion as two step process treating the capacitance of adsorption $\left(C_{a d}\right)$ as a short circuit and describing the mass transport in the solid with a capacitor ${ }^{17}$.

and corrected impedance indicates that the former is shifted with respect to the latter (Fig. 5a,b), which can be attributed to the transimpedance of the potentiostat. Although the measured impedance can still be fitted using the same equivalent circuit (Fig. 5c) ${ }^{17}$, the extracted kinetic parameters are different, as shown in Table 1 . A $5.6 \%$ error was observed for the extracted capacitance of the double layer $\left(C_{d l}\right)$. The error introduced by instrumental artefacts exceeds $10 \%$ for other parameters in the high-frequency region such as adsorption resistance $\left(R_{a d}\right)$, charge transfer resistance $\left(R_{c t}\right)$ and the resistance of the pores $\left(R_{p}\right)$. As expected, kinetic parameters of physicochemical processes occurring in the low frequency were unaffected.

Conclusion. The results shown in this paper indicate that the artefacts arising from transimpedance of the potentiostat and stray capacitance between WE-CE can be properly corrected by taking into account the equivalent circuit of the potentiostat and the frequency response of the voltage and current amplifiers. This is particularly important in dynamic impedance spectroscopy when a broadband signal is used to measure the impedance in a large range of frequencies. When current ranges above $1 \mathrm{~mA}$ are used, the impedance can be acquired with an error less than $1 \%$ in magnitude and $1^{\circ}$ in phase. The bandwidth of the potentiostat decreases with decreasing current range. The possibility to estimate the correct impedance from the measured impedance was illustrated using $2 \mathrm{k} \Omega$ and $20 \mathrm{k} \Omega$ resistors. The results indicate that it is possible to acquire the proper impedance values of the resistors up to $1 \mathrm{MHz}$ despite the use of current ranges with bandwidth as low as $100 \mathrm{kHz}$, thus extending digitally the bandwidth of the potentiostat. Using the proposed correction method, the high-frequency artefacts (inductive behaviour) observed in the measured impedance of a redox couple acquired using a current range of $1 \mathrm{~mA}$ were properly corrected. This highlights that the proposed correction method allows choosing properly 


\begin{tabular}{|l|l|l|}
\hline Parameters & Measured impedance & Corrected impedance \\
\hline$R_{u}(\Omega)$ & 18.24 & 18.67 \\
\hline$C_{d l}(F)$ & $5.64 \cdot 10^{-6}$ & $5.98 \cdot 10^{-6}$ \\
\hline$R_{a d}(\Omega)$ & 1.39 & 1.64 \\
\hline$\sigma_{a d}\left(\Omega \cdot s^{0.5}\right)$ & 57.24 & 57.92 \\
\hline$R_{c t}(\Omega)$ & 0.86 & 0.72 \\
\hline$C_{c t}(F)$ & $6.54 \cdot 10^{-3}$ & $6.56 \cdot 10^{-3}$ \\
\hline$R_{p}(\Omega)$ & 4.44 & 5.56 \\
\hline
\end{tabular}

Table 1. Extracted parameters from fitting the measured and corrected impedance of NiHCF nanoparticles in $0.5 \mathrm{M} \mathrm{K}_{2} \mathrm{SO}_{4}$ with the equivalent circuit (Fig. 5 c. $R_{u}$ denotes the uncompensated cell resistance, $C_{d l}$ is the capacitance of the double layer, $R_{a d}$ is the adsorption resistance, $\sigma_{a d}$ is the Warburg coefficient of the cation in the liquid, $R_{c t}$ is the charge transfer resistance, $C_{c t}$ is the capacitor describing the mass transport in the solid and $R_{p}$ is the pore resistance ${ }^{49}$.

\begin{tabular}{|l|l|l|l|}
\hline Parameters & Resistors & {$\left[\mathrm{Fe}(\mathrm{CN})_{6}\right]^{3-/ 4-}$} & NiHCF \\
\hline$E_{h}(\mathrm{~V})$ & 0 & 0.25 & 0.1 \\
\hline $\mathrm{f}_{\mathrm{dc}}(\mathrm{mHz})$ & - & 50 & 5 \\
\hline$\Delta \mathrm{U}_{\mathrm{dc}}(\mathrm{mVpp})$ & - & 250 & 400 \\
\hline $\mathrm{f}_{\mathrm{ac}}(\mathrm{Hz})$ & 1 & 1 & 0.35 \\
\hline$\Delta \mathrm{U}_{\mathrm{ac}}(\mathrm{mVpp})$ & $100^{*}$ & 50 & 50 \\
\hline No of Msample & 20 & 200 & 400 \\
\hline sample rate $(\mu \mathrm{s})$ & 0.2 & 0.2 & 1 \\
\hline current range $(\mathrm{mA})$ & $10^{* *}$ & 1 & 100 \\
\hline$b w(\mathrm{~Hz})$ & 2 & 2 & 1 \\
\hline
\end{tabular}

Table 2. Summary of DMFA parameters used in the acquisition of dynamic impedance. ${ }^{*}$ The amplitude of the multisine was scaled with the measured resistors to avoid errors due to current-voltage amplification. $100 \mathrm{mVpp}$ was used for the equivalent resistor $\left(R_{m}\right)$ of the current range and the amplitude used for other resistors was scaled by the ratio of the resistor to $R_{m}$ of the current range. ${ }^{* *} \mathrm{~A}$ current range of $1 \mathrm{~mA}$ was also used to investigate the effect of selecting an inappropriate current range.

the current range not only for obtaining reliable high-frequency impedance data, but also for measuring appropriately the cyclic voltammetry. The need to correct measured impedance data was illustrated using NiHCF nanoparticles, where the quantification of kinetic parameters can be severely compromised by the presence of the high-frequency artefacts.

\section{Methods}

The stray capacitance $\mathrm{CE}-\mathrm{RE}$ and the transimpedance of the potentiostat were measured using high precision resistors polarized at $0 \mathrm{~V}$ in a two-electrode cell configuration. A multisine wave consisting of 45 frequencies covering 5 decades was used as the perturbation signal. The base frequency of the multisine $\left(\mathrm{f}_{\mathrm{ac}}\right) \mathrm{was} 1 \mathrm{~Hz}$ corresponding to measuring the impedance from $1 \mathrm{MHz}$ to $8 \mathrm{~Hz}$. A summary of the parameters used for the acquisition of the impedance spectra can be found in Table 2.

$\mathrm{NiHCF}$ nanoparticles were synthesized using the co-precipitation method reported $\mathrm{in}^{42}$. The procedure consists of the simultaneous addition of $120 \mathrm{ml}$ of $50 \mathrm{mM}$ of $\mathrm{K}_{3} \mathrm{Fe}(\mathrm{CN})_{6}$ and $120 \mathrm{ml}$ of $100 \mathrm{mM}$ of Ni(NO$)_{2}$ using a flow-rate of $1 \mathrm{ml}$ per minute to $60 \mathrm{ml}$ of distilled water held at $70^{\circ} \mathrm{C}$ in a water bath while stirring constantly $\mathrm{y}^{42}$. The resulting suspension was sonicated for 30 minutes at $70^{\circ} \mathrm{C}$ and left overnight to settle. The precipitates were washed with distilled water and dried for 12 hours at $60^{\circ} \mathrm{C}$. To prepare NiHCF electrodes, $3 \mathrm{~mm}$ glassy carbon electrodes (GCE) were polished using consecutively a 2000 grit sandpaper rotating at $400 \mathrm{rpm}$, diamond suspension (Struers) of $0.250 \mu \mathrm{m}$ and $0.1 \mu \mathrm{m}$ rotating at $300 \mathrm{rpm}$. The polished electrodes were rinsed with distilled water and sonicated for three minutes to remove any diamond suspension left on the electrode surface. The cleaned GCE surface was coated using the doctor blade method $(200 \mu \mathrm{m})$ with NiHCF slurries made with a weight ratio of 80:10:10 of the synthesized NiHCF, carbon C65 (Timcal, Bodio Switzerland) and polyvinylidene fluoride (PVDF) solution in NMP (Solef S5130, Solvay) respectively.

The electrochemical measurements of the NiHCF nanoparticles and the redox couple were carried out in a three-electrode cell setup in coaxial cell geometry to reduce artefacts arising from electrode configuration ${ }^{4}$. The electrolytes used for NiHCF nanoparticles and redox couple measurement were $0.5 \mathrm{M} \mathrm{K}_{2} \mathrm{SO}_{4}$ and $20 \mathrm{mM}$ $\mathrm{K}_{3}\left[\mathrm{Fe}(\mathrm{CN})_{6}\right]$ in $1 \mathrm{M} \mathrm{KCl}$ respectively. The working electrode (WE) was the $3 \mathrm{~mm}$ modified NiHCF nanoparticle electrode or a $250 \mu \mathrm{m}$ platinum electrode depending on the system under investigation, while the counter electrode (CE) was a platinum mesh (Labor Platina). The reference electrode (RE) was a capacitively-coupled 

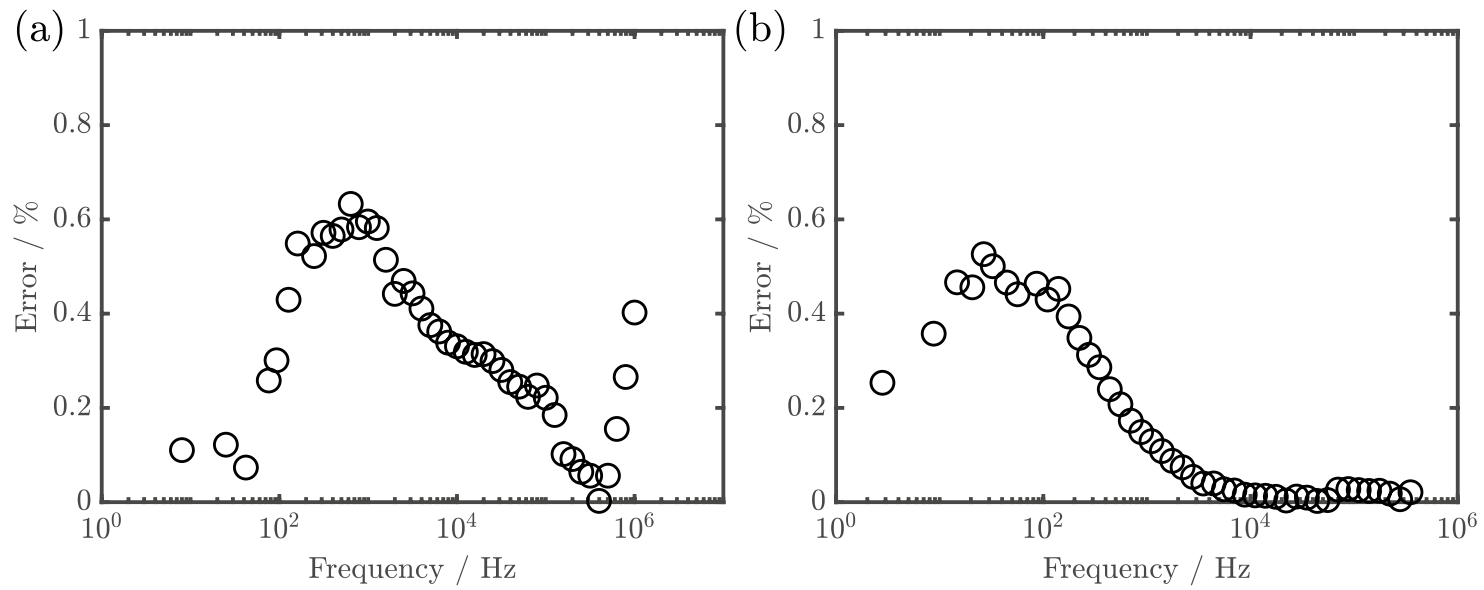

Figure 6. Plot of the estimated error due to the nonlinear component of the fundamental frequencies of dynamic impedance acquired using a multisine intensity of $50 \mathrm{mVpp}$ in $(\mathbf{a})\left[\mathrm{Fe}(\mathrm{CN})_{6}\right]^{3-/ 4-}$ redox couple (b) nickel hexacyanoferrate.

low-impedance $(20 \Omega) \mathrm{Ag} / \mathrm{AgCl}(3 \mathrm{M} \mathrm{KCl})$ fabricated by coiling a $0.1 \mathrm{~mm}$ platinum wire around the tip of a $\mathrm{Ag} / \mathrm{AgCl}$ reference electrode and connecting it through a $100 \mathrm{nF}$ capacitor to the Ag wire ${ }^{15}$. The use of this low impedance reference electrode reduces high-frequency artefacts associated with the cell setup ${ }^{4,15,18}$.

Dynamic impedance spectra were acquired by perturbing the WE electrode held at predetermined potential $\left(E_{h}\right)$, with a combined quasi-triangular waveform (QTW) and a multisine wave created by a waveform generator. The frequency of the QTW $\left(\mathrm{f}_{\mathrm{dc}}\right)$ and the amplitude $\left(\Delta \mathrm{U}_{\mathrm{dc}}\right)$ used for the $\left[\mathrm{Fe}(\mathrm{CN})_{6}\right]^{3-/ 4-}$ redox couple and NiHCF nanoparticles are shown in Table 2, which results in an equivalent scan rate of $50 \mathrm{mVs}^{-1}$ and $8 \mathrm{mVs}^{-1}$ respectively. Dynamic impedance spectra were acquired between $1 \mathrm{MHz}$ and $8 \mathrm{~Hz}$ for the $\left[\mathrm{Fe}(\mathrm{CN})_{6}\right]^{3-/ 4-}$ redox couple and $350 \mathrm{kHz}$ to $2.8 \mathrm{~Hz}$ for the NiHCF nanoparticle using the base frequency of the multisine $\left(\mathrm{f}_{\mathrm{ac}}\right)$ in Table 2 . The amplitude of the multisine $\left(\Delta U_{a c}\right)$ used for both the $\left[\mathrm{Fe}(\mathrm{CN})_{6}\right]^{3-/ 4-}$ redox couple and NiHCF nanoparticles was $50 \mathrm{mVpp}$ resulting in negligible error from the nonlinear components as shown in Fig. 6. Details of the effect of the intensity on the multisine can be found in the supporting information. The input (voltage perturbation) and output (current response) signals were measured using a two-channel oscilloscope 4262 PicoScope (Pico technology). The measured impedance was extracted with a home-made MATLAB scripts using one of the heuristic description of dynamic impedance ${ }^{32,35}$ :

$$
Z^{\prime}=\frac{i F T\left[\Delta U(\omega) \cdot g\left(\omega^{\prime}-\omega\right), b w\right]}{i F T\left[\Delta I(\omega) \cdot g\left(\omega^{\prime}-\omega\right), b w\right]}
$$

where $\Delta U$ and $\Delta I$ are the Fourier transform of the potential and current signals respectively, $\omega$ is the angular frequency, $g$ is a quadrature filter function, and $b w$ is the bandwidth of the quadrature filter (Table 2). More details about the application of the quasi-triangular waveform, dynamic multi-frequency analysis and the data extraction and evaluation can be found in $\mathrm{in}^{31,32,35}$.

\section{Data availability}

The datasets generated during and/or analysed during the current study are available from the corresponding author on reasonable request.

Received: 15 October 2020; Accepted: 22 December 2020

Published online: 14 January 2021

\section{References}

1. Bard, A. J. \& Faulkner, L. R. Electrochemical Methods: Fundamentals and Applications (eds. Bard, A. J., Faulkner, L. R., 2nd ed. edn (Wiley, New York, 2001).

2. Orazem, M. E. \& Tribollet, B. Electrochemical Impedance Spectroscopy (Wiley, New York, 2008).

3. Chan, C. K. et al. Advanced and in situ analytical methods for solar fuel materials. Top. Curr. Chem. 371, 253-324. https://doi. org/10.1007/128_2015_650(2016).

4. Battistel, A., Fan, M., Stojadinović, J. \& La Mantia, F. Analysis and mitigation of the artefacts in electrochemical impedance spectroscopy due to three-electrode geometry. Electrochim. Acta 135, 133-138. https://doi.org/10.1016/J.ELECTACTA.2014.05.011 (2014).

5. Fafilek, G. \& Breiter, M. Instrumentation for ac four-probe measurements of large impedances. J. Electroanal. Chem. 430, $269-278$. https://doi.org/10.1016/S0022-0728(97)00263-5 (1997).

6. Davis, J. E. \& Toren, E. C. Instability of current followers in potentiostat circuits. Anal. Chem. 46, 647-650. https://doi.org/10.1021/ ac60342a006 (1974).

7. Fletcher, S. The two-terminal equivalent network of a three-terminal electrochemical cell. Electrochem. commun. 3, 692-696. https ://doi.org/10.1016/S1388-2481(01)00233-8 (2001).

8. Sadkowski, A. \& Diard, J.-P. On the Fletcher's two-terminal equivalent network of a three-terminal electrochemical cell. Electrochim. Acta 55, 1907-1911. https://doi.org/10.1016/J.ELECTACTA.2009.11.008 (2010). 
9. Balabajew, M. \& Roling, B. Minimizing artifacts in three-electrode double layer capacitance measurements caused by stray capacitances. Electrochim. Acta 176, 907-918. https://doi.org/10.1016/J.ELECTACTA.2015.07.074 (2015).

10. Fan, M., Stojadinović, J., Battistel, A. \& LaMantia, F. Analysis and mitigation of electrochemical impedance spectroscopy artefacts in four-electrode cells: model and simulations. ChemElectroChem 2, 970-975. https://doi.org/10.1002/celc.201500121 (2015).

11. Khandpur, R. S. Handbook of Analytical Instruments (McGraw-Hill, London, 2007).

12. Anderson, E. L. \& Bühlmann, P. Electrochemical impedance spectroscopy of ion-selective membranes: artifacts in two-, three-, and four-electrode measurements. Anal. Chem. 88, 9738-9745. https://doi.org/10.1021/acs.analchem.6b02641 (2016).

13. Veal, B. W., Baldo, P. M., Paulikas, A. P. \& Eastman, J. A. Understanding artifacts in impedance spectroscopy. J. Electrochem. Soc. 162, H47-H57. https://doi.org/10.1007/128_2015_6500 (2015).

14. Herrmann, C. C., Perrault, G. G. \& Pilla, A. A. Dual reference electrode for electrochemical pulse studies. Anal. Chem. 40, 1173-1174. https://doi.org/10.1007/128_2015_6501 (1968).

15. Mansfeld, F. Minimization of high-frequency phase shifts in impedance measurements. J. Electrochem. Soc. 135, 906. https://doi. org/10.1007/128_2015 6502 (1988).

16. Tran, A. T., Huet, F., Ngo, K. \& Rousseau, P. Artefacts in electrochemical impedance measurement in electrolytic solutions due to the reference electrode. Electrochim. Acta 56, 8034-8039. https://doi.org/10.1007/128_2015_6503 (2011).

17. Erinmwingbovo, C., Koster, D., Brogioli, D. \& LaMantia, F. Dynamic impedance spectroscopy of nickel hexacyanoferrate thin films. ChemElectroChemhttps://doi.org/10.1007/128_2015_6504 (2019).

18. Erinmwingbovo, C. et al. Dynamic impedance spectroscopy of LiMn2O4 thin films made by multi-layer pulsed laser deposition. Electrochim. Actahttps://doi.org/10.1007/128_2015_6505 (2019).

19. Stojadinovic, J., Fan, M., Battistel, A. \& La Mantia, F. Analysis and mitigation of electrochemical impedance spectroscopy artefacts in four-electrode cells: experimental aspects. ChemElectroChem 2, 1031-1035. https://doi.org/10.1007/128_2015_6506 (2015).

20. Klink, S., Höche, D., La Mantia, F. \& Schuhmann, W. FEM modelling of a coaxial three-electrode test cell for electrochemical impedance spectroscopy in lithium ion batteries. J. Power Sources 240, 273-280. https://doi.org/10.1007/128_2015 6507 (2013).

21. Ender, M., Weber, A. \& Ivers-Tiffe, E. Analysis of three-electrode setups for AC-impedance measurements on lithium-ion cells by FEM simulations. J. Electrochem. Soc. 159, A128. https://doi.org/10.1007/128_2015_6508 (2012).

22. Klink, S. et al. The importance of cell geometry for electrochemical impedance spectroscopy in three-electrode lithium ion battery test cells. Electrochem. Commun. 22, 120-123. https://doi.org/10.1007/128_2015_6509 (2012).

23. Petrescu, B. \& Diard, J. Equivalent Model of an Electrochemical Cell Including the Reference Electrode Impedance and the Potentiostat Parasitics (Claix, Paris, 2013)

24. Bond, A. M., Schwall, R. J. \& Smith, D. E. On-line FFT faradaic admittance measurements application to A.C. cyclic voltammetry. J. Electroanal. Chem. 85, 231-247. https://doi.org/10.1016/J.ELECTACTA.2014.05.0110 (1977).

25. Stoynov, Z., Savova-Stoynov, B. \& Kossev, T. Non-stationary impedance analysis of lead/acid batteries. J. Power Sources 30, 275-285. https://doi.org/10.1016/J.ELECTACTA.2014.05.0111 (1990).

26. Van Gheem, E. et al. Electrochemical impedance spectroscopy in the presence of non-linear distortions and non-stationary behaviour Part I: Theory and validation. Electrochim. Acta 49, 4753-4762. https://doi.org/10.1016/J.ELECTACTA.2014.05.0112 (2004).

27. Darowicki, K., Ślepski, P. \& Szociński, M. Application of the dynamic EIS to investigation of transport within organic coatings. Prog. Org. Coat. 52, 306-310. https://doi.org/10.1016/J.ELECTACTA.2014.05.0113 (2005).

28. Van Gheem, E. et al. Electrochemical impedance spectroscopy in the presence of non-linear distortions and non-stationary behaviour: Part II. Application to crystallographic pitting corrosion of aluminium. Electrochim. Acta 51, 1443-1452. https://doi. org/10.1016/J.ELECTACTA.2014.05.0114 (2006).

29. Sacci, R. L. \& Harrington, D. A. Dynamic electrochemical impedance spectroscopy. ECS Trans. 19, 31-42. https://doi.org/10.1016/J. ELECTACTA.2014.05.0115 (2009).

30. Breugelmans, T. et al. Odd random phase multisine electrochemical impedance spectroscopy to quantify a non-stationary behaviour: Theory and validation by calculating an instantaneous impedance value. Electrochim. Acta 76, 375-382. https://doi. org/10.1016/J.ELECTACTA.2014.05.0116 (2012).

31. Battistel, A., Du, G. \& La Mantia, F. On the analysis of non-stationary impedance spectra. Electroanalysis 28, 2346-2353. https:// doi.org/10.1016/J.ELECTACTA.2014.05.0117 (2016).

32. Koster, D., Du, G., Battistel, A. \& La Mantia, F. Dynamic impedance spectroscopy using dynamic multi-frequency analysis: a theoretical and experimental investigation. Electrochim. Acta 246, 553-563. https://doi.org/10.1016/J.ELECTACTA.2014.05.0118 (2017).

33. Koster, D. et al. Measurement and analysis of dynamic impedance spectra acquired during the oscillatory electrodissolution of p-type silicon in fluoride-containing electrolytes. ChemElectroChem 5, 1548-1551. https://doi.org/10.1016/J.ELECT ACTA.2014.05.0119 (2018).

34. Koster, D., Zeradjanin, A. R., Battistel, A. \& La Mantia, F. Extracting the kinetic parameters of the hydrogen evolution reaction at $\mathrm{Pt}$ in acidic media by means of dynamic multi-frequency analysis. Electrochim. Actahttps://doi.org/10.1016/S0022-0728(97)00263 -50 (2019).

35. Battistel, A. \& La Mantia, F. On the physical definition of dynamic impedance: how to design an optimal strategy for data extraction. Electrochim. Acta 304, 513-520. https://doi.org/10.1016/S0022-0728(97)00263-51 (2019).

36. Pajkossy, T. Dynamic electrochemical impedance spectroscopy of quasi-reversible redox systems. Properties of the Faradaic impedance, and relations to those of voltammograms. Electrochim. Acta 308, 410-417. https://doi.org/10.1016/S0022-0728(97)00263-52 (2019).

37. Pajkossy, T. \& Mészáros, G. Connection of CVs and impedance spectra of reversible redox systems, as used for the validation of a dynamic electrochemical impedance spectrum measurement system. J. Solid State Electrochem. 24, 2883-2889. https://doi. org/10.1016/S0022-0728(97)00263-53 (2020).

38. Unwin, P. R. Introduction to electroanalytical techniques and instrumentation. Encycl. Electrochem.https://doi.org/10.1016/S0022 -0728(97)00263-54 (2007).

39. Battistel, A. Development of the Intermodulated Differential Immittance Spectroscopy for Electrochemical Analysis (2014).

40. Wessells, C. D., Peddada, S. V., Huggins, R. A. \& Cui, Y. Nickel hexacyanoferrate nanoparticle electrodes for aqueous sodium and potassium ion batteries. Nano Lett. 11, 5421-5425. https://doi.org/10.1016/S0022-0728(97)00263-55 (2011).

41. Erinmwingbovo, C., Palagonia, M., Brogioli, D. \& La Mantia, F. Intercalation into a prussian blue derivative from solutions containing two species of cations. ChemPhysChemhttps://doi.org/10.1016/S0022-0728(97)00263-56 (2017).

42. Trócoli, R., Battistel, A. \& LaMantia, F. Nickel hexacyanoferrate as suitable alternative to ag for electrochemical lithium recovery. ChemSusChem 8, 2514-2519. https://doi.org/10.1016/S0022-0728(97)00263-57 (2015).

43. Trócoli, R., Erinmwingbovo, C. \& La Mantia, F. Optimized lithium recovery from brines by using an electrochemical ion-pumping process based on $\lambda-\mathrm{MnO}_{2}$ and nickel hexacyanoferrate. ChemElectroChemhttps://doi.org/10.1016/S0022-0728(97)00263-58 (2017).

44. Palagonia, M. S., Brogioli, D. \& Mantia, F. L. Influence of hydrodynamics on the lithium recovery efficiency in an electrochemical ion pumping separation process. J. Electrochem. Soc. 164, E586-E595. https://doi.org/10.1016/S0022-0728(97)00263-59 (2017).

45. Palagonia, M. S., Brogioli, D. \& La Mantia, F. Effect of current density and mass loading on the performance of a flow-through electrodes cell for lithium recovery. J. Electrochem. Soc. 166, E286-E292. https://doi.org/10.1021/ac60342a0060 (2019). 
46. Palagonia, M. S., Brogioli, D. \& La Mantia, F. Lithium recovery from diluted brine by means of electrochemical ion exchange in a flow-through-electrodes cell. Desalination 475, 114192. https://doi.org/10.1021/ac60342a0061 (2020).

47. Trocoli, R., Bidhendi, G. K. \& La Mantia, F. Lithium recovery by means of electrochemical ion pumping: a comparison between salt capturing and selective exchange. J. Phys. Condens. Matter 28, 114005. https://doi.org/10.1021/ac60342a0062 (2016).

48. Xie, N., Li, Y., Lu, Y., Gong, J. \& Hu, X. Electrochemically controlled reversible lithium capture and release enabled by $\mathrm{LiMn}_{2} \mathrm{O}_{4}$. ChemElectroChem 7, 105-111. https://doi.org/10.1002/celc.201901728 (2020).

49. Erinmwingbovo, C. Kinetics of the reversible insertion of cations in positive electrode materials under dynamic conditions, https ://doi.org/10.26092/elib/153 (2020).

\section{Acknowledgements}

The authors gratefully acknowledge the support of the European Research Council (ERC) under the European Union's Horizon 2020 research and innovation programme (Grant Agreement Number 772579).

\section{Author contributions}

C.E. wrote the main manuscript text, prepared the figures, performed the experiments; F.L.M. developed the theory. All authors revised the manuscript.

\section{Funding}

Open Access funding enabled and organized by Projekt DEAL.

\section{Competing interests}

The authors declare no competing interests.

\section{Additional information}

Supplementary Information The online version contains supplementary material available at https://doi. org/10.1038/s41598-020-80468-x.

Correspondence and requests for materials should be addressed to F.L.M.

Reprints and permissions information is available at www.nature.com/reprints.

Publisher's note Springer Nature remains neutral with regard to jurisdictional claims in published maps and institutional affiliations.

(c) (i) Open Access This article is licensed under a Creative Commons Attribution 4.0 International License, which permits use, sharing, adaptation, distribution and reproduction in any medium or format, as long as you give appropriate credit to the original author(s) and the source, provide a link to the Creative Commons licence, and indicate if changes were made. The images or other third party material in this article are included in the article's Creative Commons licence, unless indicated otherwise in a credit line to the material. If material is not included in the article's Creative Commons licence and your intended use is not permitted by statutory regulation or exceeds the permitted use, you will need to obtain permission directly from the copyright holder. To view a copy of this licence, visit http://creativecommons.org/licenses/by/4.0/.

(C) The Author(s) 2021 